\title{
Editorial
}

\section{Mixed Matrix Membranes: A New Asset for Blood Purification Therapies}

\author{
M.S.L. Tijink ${ }^{a, b} \quad$ J. Kooman ${ }^{c} \quad$ M. Wester ${ }^{d} \quad$ J.Sun ${ }^{b, e} \quad$ S. Saiful ${ }^{b} \quad$ J.A. Joles ${ }^{d}$ \\ Z. Borneman ${ }^{b}$ M. Wessling ${ }^{b}$ D.F. Stamatialis ${ }^{a}$ \\ a Institute for Biomedical Technology and Technical Medicine MIRA, Biomaterials Science and Technology, and \\ ${ }^{\mathrm{b}}$ Membrane Technology Group, Faculty of Science and Technology, University of Twente, Enschede, 'Department \\ of Internal Medicine, University Hospital Maastricht, Maastricht, and d Department of Nephrology and Hypertension,

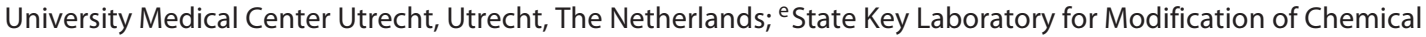 \\ Fibers and Polymer Materials, College of Material Science and Engineering, Donghua University, Shanghai, PR China
}

Hemodialysis is a very effective treatment strategy for removal of small-molecular-weight solutes but it is inefficient in removing larger-molecular-weight substances (among which are important uremic toxins such as $\beta_{2^{-}}$ microglobulin) and protein-bound uremic toxins [1]. Convective therapies such as hemodiafiltration, which could improve removal of $\beta_{2}$-microglobulin, do not show an improvement in all-cause mortality [2]. Combination of hemodialysis with adsorption columns has been proposed to increase the clearance of hard-to-remove molecules [3]; however, direct blood contact with sorbents is associated with poor biocompatibility. Given the high costs, relative complexity and drawbacks of sorbent-augmented dialysis treatment, a combination of adsorption and membrane separation within a single module would be an important asset for extracorporeal therapy [4-6]. In fact, Ronco [4] asked the membrane manufacturers to consider the possibility of mixing the biomaterial of a specific membrane with a sorbent material based on a significant enhancement of internal filtration and backfiltration in hollow-fiber hemodialyzers. Recently, some of the authors of this editorial proposed a combination of diffusion and

\section{KARGER}

E-Mail karger@karger.com

www.karger.com/bpu adsorption in one membrane, the so-called mixed matrix membrane (MMM), for removal of uremic solutes [7-9]. The MMM concept had been proposed earlier as an alternative to traditional chromatographic columns [10].

In an MMM, adsorptive particles are incorporated in a macroporous membrane matrix. A particle-free membrane layer is introduced on the blood-contacting side of the membrane, with the aim of improving membrane hemocompatibility and preventing particle release into the circulation and hence formation of emboli (fig. 1a). Mixed matrix flat-sheet and hollow-fiber membranes have been developed via phase inversion (fig. 1b, c, 2) [7-9]. For the macroporous matrix, cellulose acetate [7] or a polyethersulfone (PES)/polyvinylpyrrolidone (PVP) polymer blend (PES as a membrane-forming polymer blended with PVP to improve hydrophilicity) $[8,9]$ were used. In both cases, activated carbon was used as the adsorptive particle. The MMM combined diffusion and adsorption in one step (fig. 1d) and was successfully applied for removal of creatinine $[7,8]$ and various protein-bound toxins including para-aminohippuric acid, hippuric acid, indoxyl sulfate (IS) and $p$-cresylsulfate $[8,9]$. For example,
(C) 2014 S. Karger AG Basel

0253-5068/14/0371-0001\$39.50/0
D.F. Stamatialis

Institute for Biomedical Technology and Technical Medicine MIRA Biomaterials Science and Technology, Faculty of Science and Technology University of Twente, PO Box 217, NL-7500 AE Enschede (The Netherlands) E-Mail d.stamatialis@utwente.nl 

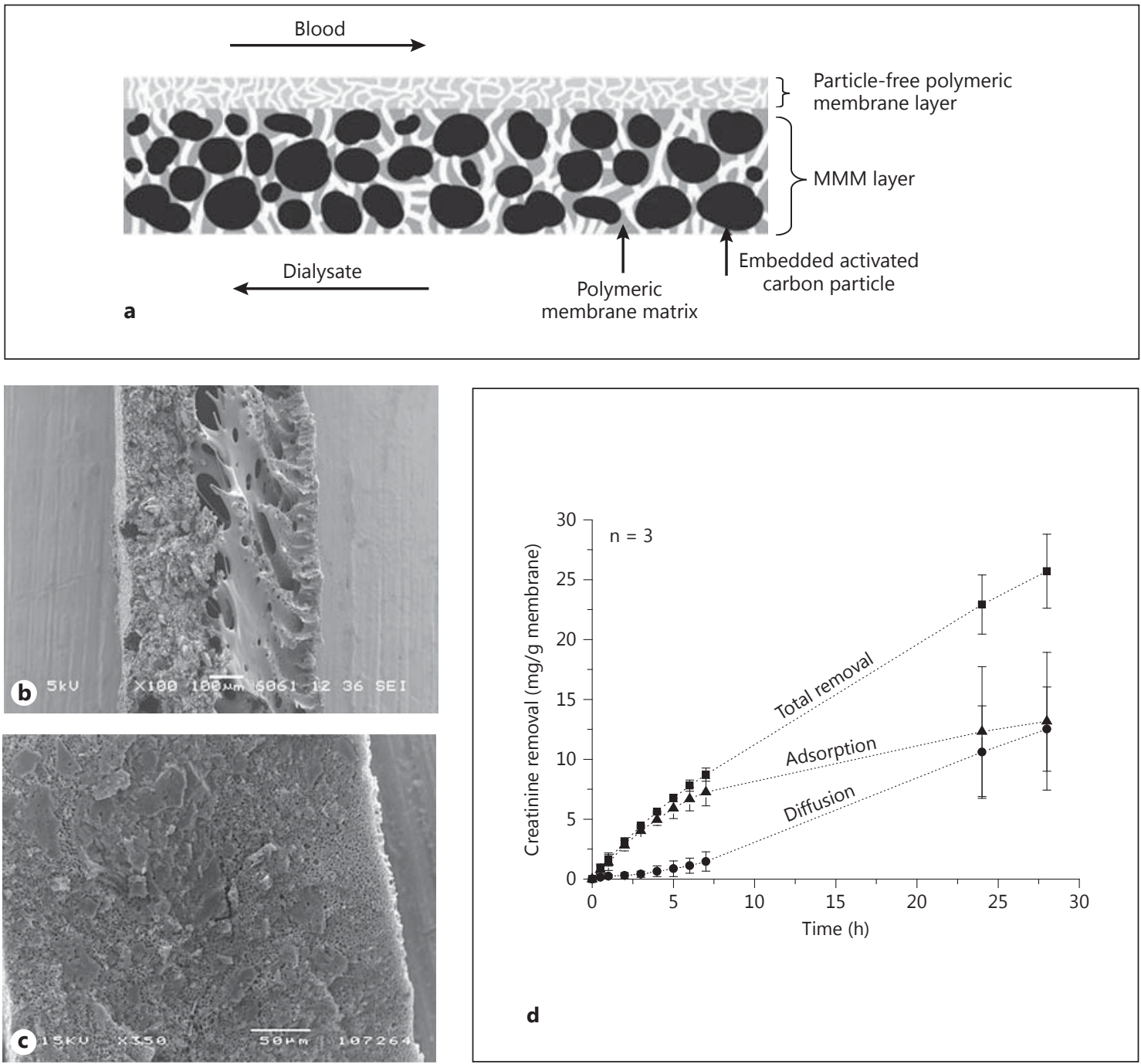

Fig. 1. Dual-layer MMM. a Concept. b, c Scanning electron microscopy images of PES/PVP- and cellulose acetate-based flat membranes, respectively. $\mathbf{d}$ Average creatinine total removal, diffusion and adsorption over time using a flat MMM. a, b, d Reprinted from Tijink et al. [8], with permission from Elsevier.
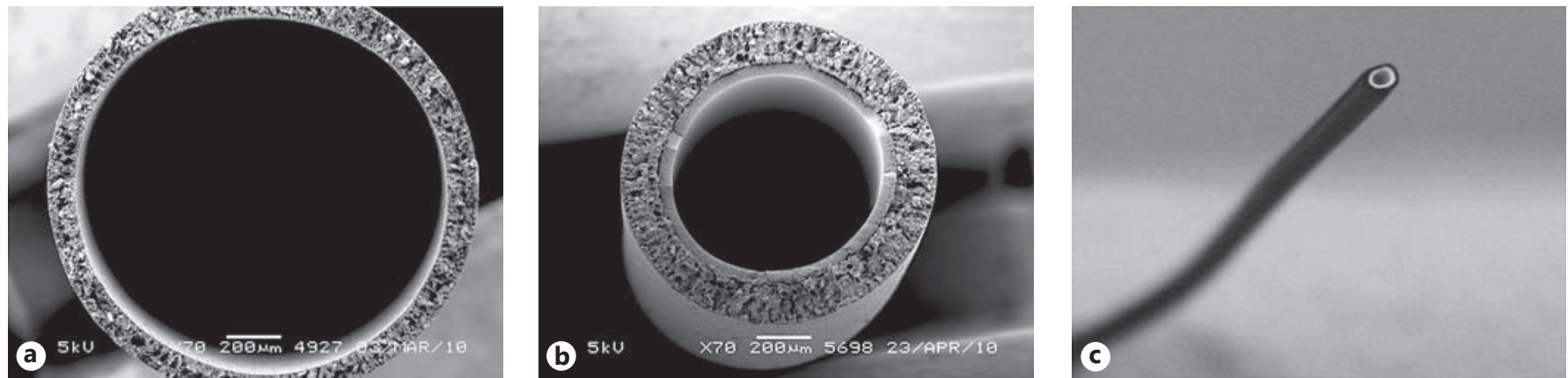

Fig. 2. Hollow-fiber MMM. a, b Scanning electron microscopy images of a single- and dual-layer membrane, respectively. c Photo of a dual-layer MMM. b, c Reprinted from Tijink et al. [9], with permission from Elsevier. 


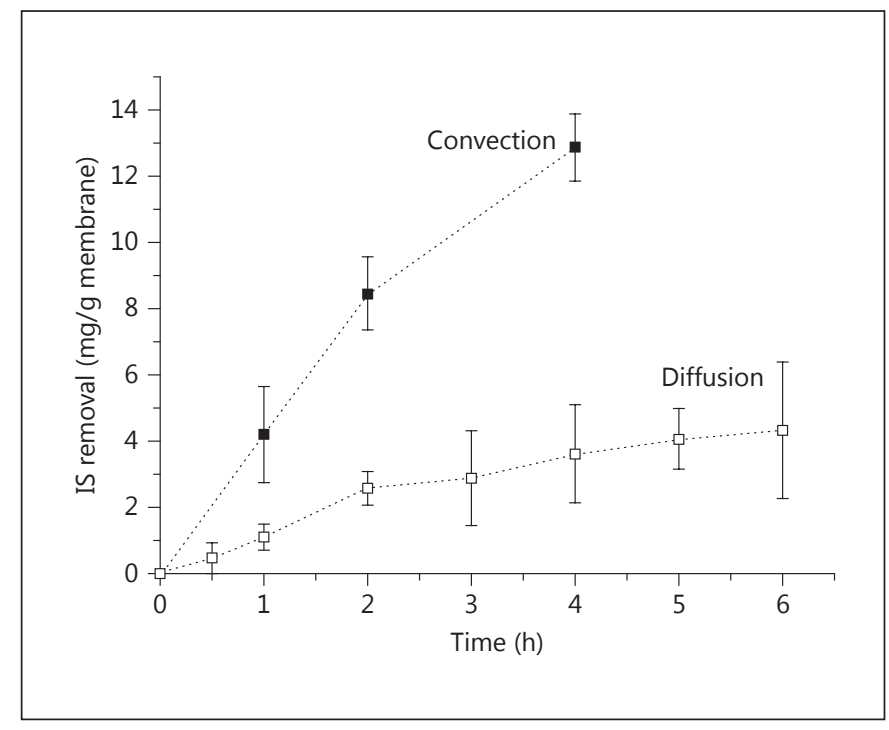

Fig. 3. Removal of IS under diffusion and convection experiments $(n=3)$. Dotted lines are plotted to guide the eye. Adapted from Tijink et al. [9].

figure 3 compares the removal of IS under diffusion and convection modes (adapted from Tijink et al. [9]) and shows that the amount adsorbed in the second case is higher, probably due to higher accessibility of the MMM due to the applied pressure difference. It is important to note that in diffusion experiments, albumin is retained by the membrane, whereas in convection experiments, albu- min partially passes through the membrane together with a lot of fluid. In both cases, the toxin removal occurs without significant changes to the $\mathrm{pH}$ or osmolarity of the plasma [9]. In a recent study, addition of activated carbon particles to the dialysate compartment of a hemodialyzer led to improved protein-bound toxin clearance because of a continuous driving force [11]. Our results show that their incorporation into the MMM can also improve the driving force for protein-bound toxins and hence enhance their removal. In the future, we plan to incorporate other types of activated carbon as well as other sorbents such as hydrotalcites, which have high affinity to phosphate [12]. The pore size of the particle-free layer will also be tailored, and MMMs for low- and high-flux hemodialysis or hemodiafiltration will be constructed.

Besides removal of protein-bound toxins, the MMM might also be useful in liver failure or sepsis by combining renal support and targeted adsorption. Finally, an MMM might also be useful for a wearable artificial kidney due to the incorporation of sorbents within a membrane. Admittedly, their development is still at a relatively early stage, and various challenges need to be addressed. The membranes should be extensively tested for efficacy, biocompatibility and safety.

\section{Acknowledgements}

M.S.L. Tijink would like to thank the Dutch Kidney Foundation for financial support.

\section{References}

$>1$ Basile C, Libutti P, Di Turo AL, Casino FG, Vernaglione L, Tundo S, Maselli P, De Nicolò EV, Ceci E, Teutonico A, Lomonte C: Removal of uraemic retention solutes in standard bicarbonate haemodialysis and longhour slow-flow bicarbonate haemodialysis. Nephrol Dial Transplant 2011;24:1296-1303.

-2 Grooteman MPC, van den Dorpel MA, Bots ML, Penne EL, van der Weerd NC, Mazairac $\mathrm{AH}$, den Hoedt $\mathrm{CH}$, van der Tweel I, Lévesque R, Nubé MJ, ter Wee PM, Blankestijn PJ; CONTRAST Investigators: Effect of online hemodiafiltration on all-cause mortality and cardiovascular outcomes. J Am Soc Nephrol 2012;23:1087-1096.

$>3$ Davankov VA, Pavlova LA, Tsyurupa MP, Tur DR: Novel polymeric solid-phase extraction material for complex biological matrices. Portable and disposable artificial kidney. J Chromatogr B Biomed Sci Appl 1997; 689:117-122.
-4 Ronco C: Sorbents: from bench to bedside. Can we combine membrane separation processes and adsorbent based solute removal? Int J Artif Organs 2006;29:819-822.

$\checkmark 5$ Formica M, Inguaggiato P, Bainotti S, Wratten ML: Coupled plasma filtration adsorption. Contrib Nephrol 2007;156:405-410.

$\checkmark 6$ Nalesso F, Brendolan A, Crepaldi C, Cruz D, de Cal M, Bellomo R, Ronco C: Albumin dialysis and plasma filtration adsorption dialysis system. Contrib Nephrol 2007;156:411418.

7 Saiful S: Mixed Matrix Membrane Adsorbers for Protein and Blood Purification; PhD thesis, University of Twente, Enschede, 2007, p 162.

$>$ Tijink MSL, Wester M, Sun J, Saris A, Bolhuis-Versteeg LA, Saiful S, Joles JA, Borneman Z, Wessling M, Stamatialis DF: A novel approach for blood purification: mixed-matrix membranes combining diffusion and adsorption in one step. Acta Biomater 2012;8: 2279-2287.
-9 Tijink MSL, Wester M, Glorieux G, Gerritsen KG, Sun J, Swart PC, Borneman Z, Wessling M, Vanholder R, Joles JA, Stamatialis D: Mixed matrix hollow fiber membranes for removal of protein-bound toxins from human plasma. Biomaterials 2013;34:7819-7828.

10 Avramescu ME, et al: Preparation of mixed matrix adsorber membranes for protein recovery. J Membr Sci 2003;218:219-33.

$\checkmark 11$ Meyer TW, Peattie JW, Miller JD, Dinh DC, Recht NS, Walther JL, Hostetter TH: Increasing the clearance of protein-bound solutes by addition of a sorbent to the dialysate. J Am Soc Nephrol 2007;18:868-874.

12 Kuzawa K, Jung YJ, Kiso Y, Yamada T, Nagai M, Lee TG: Phosphate removal and recovery with a synthetic hydrotalcite as an adsorbent. Chemosphere 2006;62:45-52. 